I dentification of dead tree of Japanese oak wi It (Jow using hi gh spatial resol ut i on sat el I i te i magery

\begin{tabular}{|c|c|}
\hline 著者 & $\begin{array}{l}\text { Komur a Ry ot ar o, Kanat a Naot o, Kubo Namor u, } \\
\text { Mur ambt o Ken- i chi r o }\end{array}$ \\
\hline $\begin{array}{l}\text { j our nal or } \\
\text { publ i cat i on title }\end{array}$ & $\begin{array}{l}\text { Envi r onment al Moni tori ng I n East Asi a ; Renot e } \\
\text { Sensi ng and For est s }\end{array}$ \\
\hline page $r$ ange & 75- 78 \\
\hline year & 2005-01-01 \\
\hline URL & ht t p: //hdl . handl e. net /2297/6328 \\
\hline
\end{tabular}




\title{
Identification of Dead Tree of Japanese Oak Wilt (JOW) using High Spatial Resolution Satellite Imagery
}

\author{
Ryotaro KOMURA*, Naoto KAMATA**, Mamoru KUBO** and Ken-ichiro MURAMOTO** \\ *Electronics and Information Engineering Course, Ishikawa National College of Technology \\ Kitacyujo, Tsubata, Kahoku-gun, Ishikawa, 929-0392 JAPAN \\ **Graduate School of Natural Science and Technology, Kanazawa University \\ Kanazawa, Ishikawa, 920-1192, JAPAN
}

\begin{abstract}
The incidence of Japanese oak wilt (JOW) has been increasing in Japan since late 1980s. The JOW is caused by the ambrosia fungus Raffaelea quercivorus vectored by an ambrosia beetle Platypus quercivorus. Detection of trees killed by JOW is important to prevent new incidence of JOW but difficult because most of JOW mortality occurs in mountainous area. Remote sensing with high spatial resolution imageries taken by IKONOS ${ }^{\circledR}$ or Quickbird ${ }^{\circledR}$ can be laborsaving technology to identify individual trees killed by JOW over wide areas. A purpose of this study is to develop a laborsaving image processing technique to identify individual tree crowns. The orthophoto imagery was transformed both to HSI (Hue, Saturation, and Intensity) and NDVI (Normalized Difference Vegetation Index) datasets. Individual dead tree crowns killed by JOW were identified by cluster analysis using datasets of $H, S$, and NDVI.
\end{abstract}

\section{INTRODUCTION}

The incidence of Japanese oak wilt (JOW) has been increasing in Japan since late 1980s. The JOW is caused by the ambrosia fungus Raffaelea quercivorus vectored by an ambrosia beetle Platypus quercivorus. A large number of oak trees have been killed by the disease complex. Detection of individual trees killed by JOW is important for control of JOW but difficult because most of JOW mortality occurs in mountainous area. Komura et al. [1] used aerial photographs to distinguish tree crowns killed by JOW from living trees by their color. However, aerial photographs include much more topographic distortion than satellite imageries, which makes image processing to identify dead trees more difficult. Remote sensing with high spatial resolution imageries taken by IKONOS $(\AA$ or Quickbird $(\mathbb{R}$ can be laborsaving technology to identify individual trees killed by JOW over wide areas. A purpose of this study is to develop a laborsaving image processing technique to identify individual tree crowns killed by JOW.

\section{MATERIALS AND METHODS}

\section{A. Satellite data}

IKONOS $®$ satellite imagery with RPC data of areas around Mt. Kariyasu, Ishikawa, Japan was used in this study. New incidences of JOW occur from mid-July to early September. Hence, bright red color of tree crowns killed by JOW could be easily differentiated from green color of living tree crowns by September. However, high spatial resolution

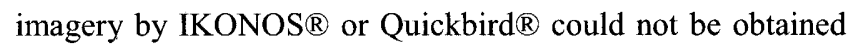
because of cloud coverage. In October, the identification of JOW was difficult because of natural fall color of living trees. Clear IKONOS $®$ imagery of the target area was obtained in May 2003. Trees killed by JOW in 2002 can be identified using satellite imagery taken in May 2003 because these trees still hold dark brown wilted foliage.

IKONOS ${ }^{\circledR}$ imagery is consisting of the blue (B), green $(G)$, red (R), and near-infrared (NIR) bands and PAN data. The spatial resolutions of $R, G, B$ and NIR bands were 4 $\mathrm{m} /$ pixel and that of PAN data was $1 \mathrm{~m} /$ pixel. The $10 \mathrm{~m} /$ pixel DEM topography dataset (Terrain ${ }^{\circledR}$, Hokkaido-chizu co., Ltd.) was used.

\section{B. Analysis methods}

Fig. 1 shows the process of the identification of killed trees. Orthophoto images of R, G, B and NIR band data were created using PAN image and DEM on GIS (TNTmips). The spatial resolution of orthophoto imagery was $1 \mathrm{~m} /$ pixel. Fig. 2 shows the IKONOS $®$ satellite image $(1800 \times 1800$ pixels $)$ used in this study. For an area of $240 \times 180 \mathrm{~m}$ (Figs. $2 \& 3$ ), crowns of trees killed by JOW in 2002 were detected 


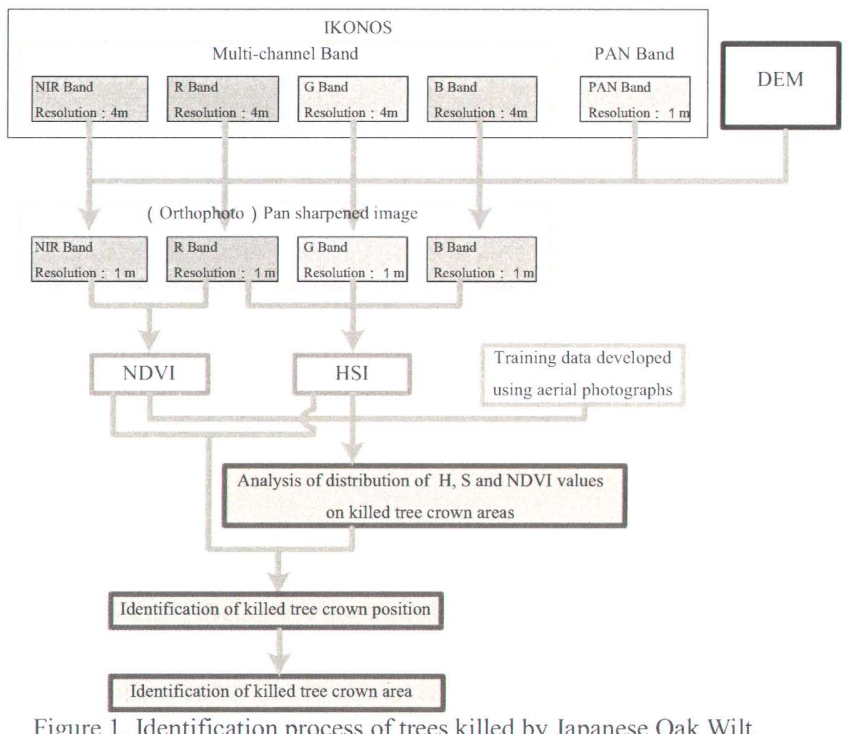

Figure 1. Identification process of trees killed by Japanese Oak Wilt.

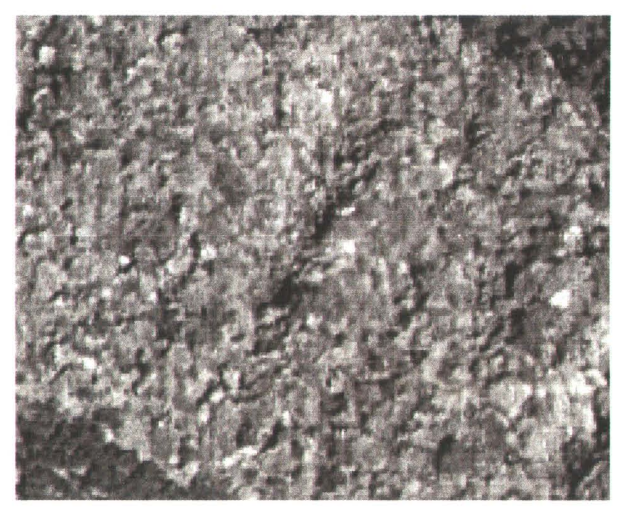

Figure 3. Magnified IKONOS imagery corresponding to a white rectangular area in Fig. 2, in which evaluation of results was conducted. $(240 \times 180$ pixels, $1 \mathrm{~m} /$ pixel, May 2003$)$

manually and plotted on GIS (Fig. 4). This distribution map of JOW was used for evaluation of identification using satellite images. Identification of tree crowns killed by JOW was more difficult in May 2003 than in October 2002 because of changes in color of wilted foliage. However, IKONOS ${ }^{\circ}$ data include near-infrared (NIR) band data that can be used in vegetation analysis. Therefore, we used NIR as well as R, G and $\mathrm{B}$ bands for identification using $\operatorname{IKONOS}{ }^{\circledR}$ imagery taken in May.

The analysis in this study was based on a method used for a similar analysis using aerial photographs [1]. The dataset of R, G and B bands was transformed to HSI dataset, which consists of $H$ (Hue), $S$ (Saturation), and $I$ (Intensity) images.

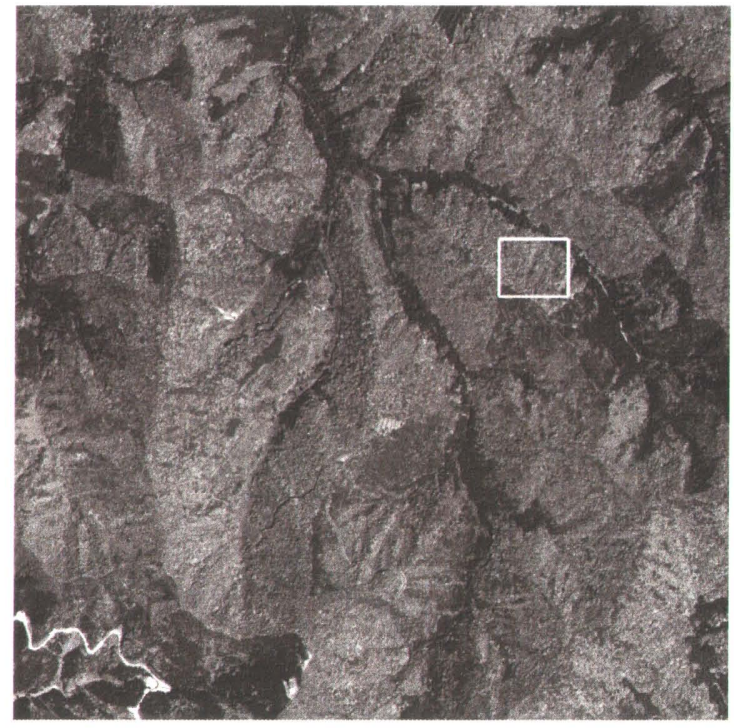

Figure 2. IKONOS imagery used for analysis $(1800 \times 1800$ pixels, 1 $\mathrm{m} /$ pixel, May 2003)

Results of the analysis were evaluated in a white rectangular area ( $c f$. Figs. 3 and 7).

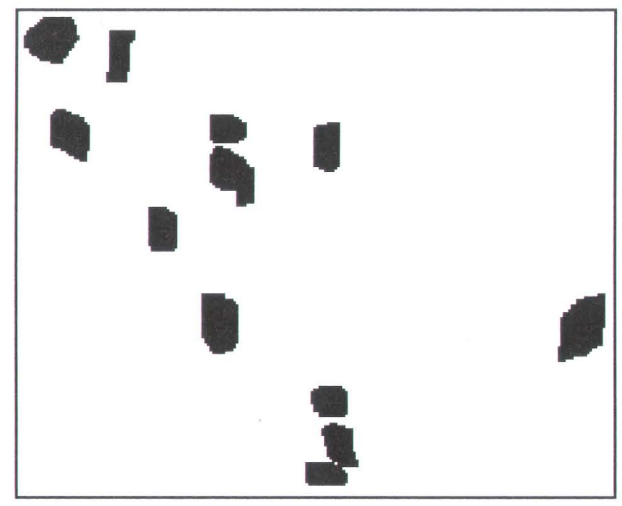

Figure 4. Distribution of tree crowns killed by Japanese Oak Wilt in 2002, which was produced using aerial photographs taken in Oct. 2002. The area corresponds to Fig. 3 .

Color of each crown was plotted on a two-dimensional polar coordinate described as $(S, H)$. The distribution were compared between dead trees and living ones. The NDVI (Normalized Difference Vegetation Index) was calculated from $R$ and NIR bands using following equation:

$$
N D V I=\frac{N I R-R}{N I R+R}
$$

The values of NDVI were between -1 and 1 . The value increased with vegetation activity. The frequency of the NDVI was compared between dead trees and living ones.

The maximum-likelihood method was employed to determine thresholds of $H, S$ to divide living and dead trees on a two-dimensional polar coordinate $(S, H)$ and a threshold of 
$N D V I$ values to divide living and dead trees on frequencies of NDVI. Pixels were identified as killed trees when all of the three values $(H, \mathrm{~S}$, and $N D V I)$ were smaller than each of the thresholds. After the identification, dead tree crowns were determined by an approximation to a cluster of circles by algorithms developed by Komura et al. [2][3].

\section{RESULTS AND DISCUSSIONS}

Fig. 5 shows the distribution of $H$ and $S$ values for both living and dead tree crowns. Both the values tended to be smaller in dead trees. The value $I$ was not used because it was strongly influenced by solar radiation. A pie enclosed by S-axis and $(14,0.37)$ was a likely border between living and dead trees. Therefore, $(14,0.37)$ were employed as the thresholds of $(H, S)$.

Fig. 6 shows frequencies of $N D V I$ values for living and dead tree crowns. NDVI values tended to be smaller in dead trees supporting that NDVI is an indicator of chlorophyll content. By the maximum likelihood method, we employed 0.57 as a threshold of $N D V I$ value.

Fig. 7 shows estimated areas of tree crowns killed by JOW, which were calculated using satellite imagery. Comparing the result (Fig. 7) with training data obtained from manual detection from aerial photographs (Fig. 4), identification using high-resolution satellite imagery was overestimation: All dead crowns that had been detected in training data were identified as dead tees. However, many living crowns were misidentified as dead trees. Furthermore, shapes of killed tree crowns differed between the results from satellite imagery and those manually detected from aerial photographs.

In our study, results obtained from satellite imagery seemed not so good as those from aerial photographs. The major reasons were probably detection method and season of data acquisition. Dead crowns were detected manually from aerial photographs but identified automatically from satellite imagery. Aerial photographs were taken in early October, in which crowns of trees killed by JOW are still bright red. However, satellite imagery was taken in May, in which the color changed to dark brown. These were the likely causes that results obtained from satellite imagery seemed worse. We speculate that satellite imagery would be useful as aerial photographs taken in the same season because satellite imagery provides NIR band that is not available in aerial photographs.

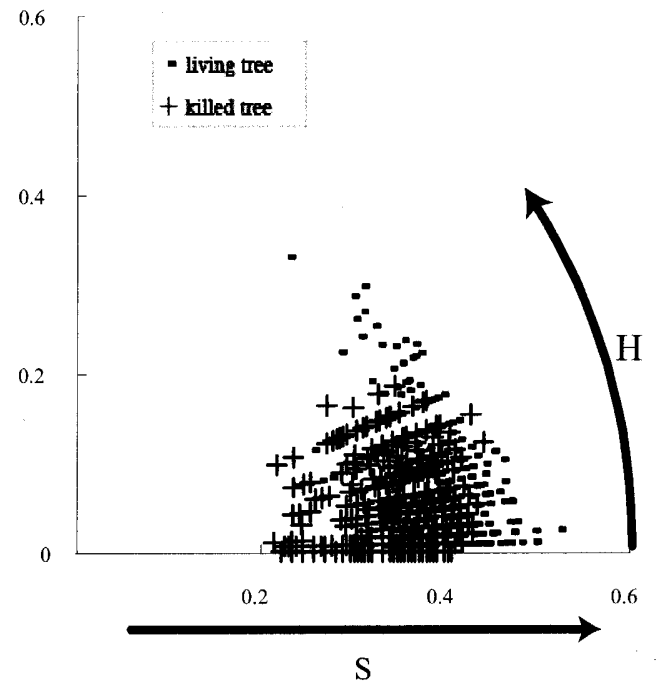

Figure 5. Distribution of $\mathrm{H}$ (Hue) and S (Saturation) values on living tree and killed tree areas.

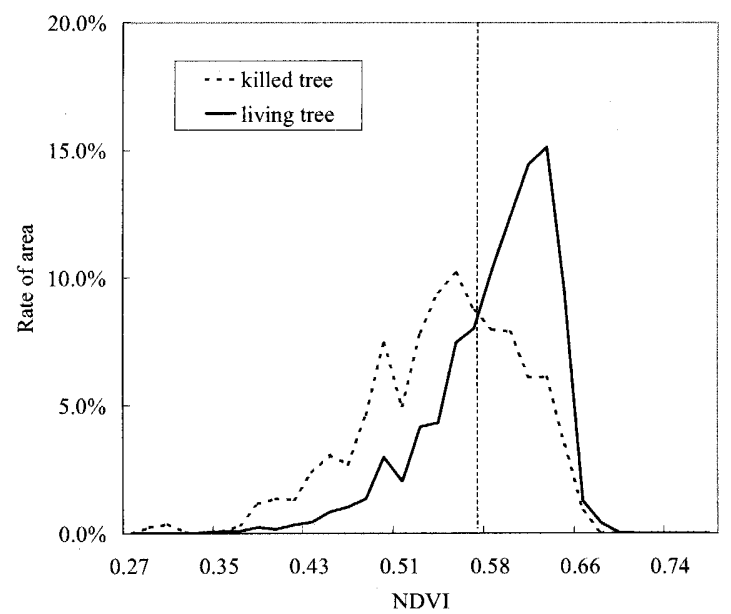

Figure 6. Distribution of NDVI values on living tree and killed tree areas

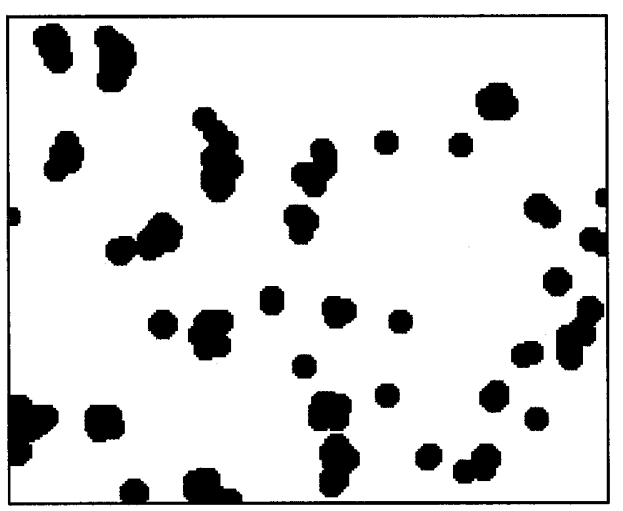

Figure 7. Results of identification with IKONOS images $(240 \times 180$ pixels $)$ 


\section{CONCLUSIONS}

In May, crown of trees killed by JOW was difficult to be distinguished from living trees because of its dark brown color. Using $\mathrm{H}, \mathrm{S}$ and NDVI images of IKONOS $®$ imagery, automatic identification overestimated JOW incidences but did not fail to detect dead trees that had been manually detected from aerial photographs taken in October. In future, an automatic technique to realize more accurate identification of JOW incidences using satellite imageries will be developed by overlaying data taken in successive years.

\section{REFERENCES}

[1] R. Komura, K. Esaki, M. Kubo, K. Muramoto, N. Kamata, "Identification of dead tree of japanese oak wilt (JOW) using aerial photographs," Proceedings of 53th symposium of chubu branch of Japanese forest society, pp. 12, 2004.

[2] R. Komura, M. Kubo, N. Kamata, K. Muramoto, "Analysis of Size of Tree Crown on Aerial Image Using Circle Unification," SICE Annual Conference 2003 in Fukui(SICE2003), pp.1962-1966, 2003.

[3] R. Komura, M. Kubo, K. Muramoto, "Delineation of tree crown in high resolution satellite image using circle expression and watershed algorithm," Proceedings of IEEE IGARSS 2004, vol, 3, pp. 1577-1580, 2004. 